\title{
Different Aspects of Multiculturalism and Challenges of Multicultural Co-existence in Ethiopia
}

\author{
Mulugeta Nega \\ College of Social Science and Humanities, Debre Markos University
}

\begin{abstract}
This study in general underpins the issues of multicultural co-existence in Ethiopia. Specifically the study identified the different aspects of multiculturalism. The study has addressed the challenges of multiculturalism in general and the problems of multicultural co-existence in Ethiopia. To do this the study has used a purely qualitative research methodology. In this study the researcher has also employed phenomenological research design with the help of document review analysis technique. The study identified three forms of multiculturalism, i.e. democratic, conservative and critical. In addition in this study it is investigated that multiculturalism can avoid marginalization that resulted because of neglected past history, can create harmony in between inter- ethnic and inter- racial identities and also consolidates representation in one's own identity in the political sphere of a country. The presence of institutional gap, lack of efficiency coupled with extreme ethnic feelings were identified as the main sources of the problem among others that can deter multicultural co- existence in Ethiopia. Finally the study recommended that marginalization and extreme ethnic feelings should be avoided if and only if the concerned bodies like government, religious institutions and other stakeholders thought about the evilness of the problem.
\end{abstract}

Keywords: Multiculturalism, Co-existence, Challenges

DOI: $10.7176 / \mathrm{DCS} / 10-3-01$

Publication date: February $29^{\text {th }} 2020$

\section{Introduction}

\subsection{The Concept of Culture}

Culture is a collection of a number of different spiritual, materials, intellectual and emotional features of a social group, and in addition it includes art and literature, lifestyles, ways of living together, value systems, traditions and beliefs (UNESCO, 2002). It is the product of physical artifacts and intangible attributes of a certain social group that are inherited from past generations, maintained in the present and reserved for the benefit of future generations. Culture also manifests itself in diverse forms, from mega-structures, like pyramids, medieval cities, monastic complexes and museums, to languages and dialects, songs, art, folk stories, customs, practices and dances. Culture is socially constructed and learned phenomena. It has is comprised of elements like language, values and norms (Kymilka, 2001). It often refers to the ensemble of arts, food, dress and other aesthetic variations that distinguish one social group from another. It is also the systems of representation, meaning, belief, and other ideological variations between social groups. Culture is dynamic which varies from place to place and across time. It is not something fixed rather its fluid. It can also pass from generation to generation through the process of socialization (Fleras, 2009).

Culture helps society hold together. It gives people a sense of belongingness, instructs them in how to behave and tells them what to think in particular situations. Culture basically consists of the various groups to which a person belongs. It is not inherited or scientific rather it is a social concept unique to the human race. So culture is shared, symbolic, and multifaceted and learned (Ibid).

\section{The Meaning of Multiculturalism}

Multiculturalism is a new word. People have lived in societies which were, for much of their history, multicultural. So what is distinctive about the idea is the coexistence of cultural, ethnic and religious communities within one political society or within one state(RAZ J.,1998). Different descriptions and definitions come readily to mind when the term "multicultural" is brought to the fore. It describes the existence, acceptance, and promotion of multiple cultural traditions within a single jurisdiction, usually considered in terms of the culture associated with an aboriginal ethnic group and foreigner ethnic groups. Multicultural and Multiculturalism is the word frequently used to describe the ethnic diversity. It represents a society in which the several cultures co-exist, that is it is a society, state, a nation, a country, a region or even a geographical location as town or school, which is comprised of people who belong to different cultures (Ojeah, 2018).

Multiculturalism describes the existence, acceptance, and the promotion of multiple cultural traditions within a single jurisdiction, usually considered in terms of the culture associated with an aboriginal ethnic group and foreigner ethnic groups. Multicultural society can be seen as one which incorporates ideas, beliefs, or people from many different countries and cultural backgrounds. Multicultural policies vary widely, ranging from the advocacy of equal respect to the various cultures in a society, to a policy of promoting the maintenance of cultural diversity, and to policies in which people of various ethnic and religious groups are addressed by the authorities as defined 
by the group to which they belong. In one breath, the term can be understood to encompass a wide variety of concerns that are connected to the engagement and management of the challenges and prospects of diversity in contemporary societies(Ojeah, 2018).

Oxford Advanced Learners Dictionary defines multiculturalism as the practice of giving importance to all cultures in a society and it includes people of several, different races, religions, languages and traditions. Multiculturalism is a catchall term that refers generally to a set of related cultural movements and trends which emphasize the diversity of a country's culture and society. It recognizes, encourage, and affirm the participation of ethnic minorities in all aspects of a state's life. People of a country tend to celebrate the contributions made by diverse groups and to consider those contributions as vital to the economic, social, and cultural fabric of the state (Mendible M., 1999). Multiculturalism means the appreciation, acceptance, and promotion of various cultures in schools, businesses, cities or nations. It expresses the respect for diversity, and advocates equitable status to distinct ethnic and religious groups. It is compared to 'bowl of salad' where every piece maintains its taste and adds to total.

Multicultural and Multiculturalism are the words frequently used to describe the ethnic diversity. Multiculturalism denotes a society in which the several cultures co-exist. It means that it is a society, state, a nation, a country, a region or even a geographical location as town or school, which is composed of people who belong to different cultures. The terms like plural society or cosmopolitan society were used earlier to describe the same phenomenon. The words multiracial or poly-ethnic or multiethnic societies were also used. Multicultural, however, is the preferred term. It is so, because the word culture in multicultural has positive connotations. The word race is word of suspect, whereas the word culture seems celebrated and related with distinctive way of life. Hence, multiculturalism is a political idea about the proper way to respond to cultural diversity. It's about for more inclusive conception of citizenship, justice and democracy which extend special recognition and rights to cultural minority groups. It stands for a wide range of potential and existing processes and public policies within a nation state where minority collectivities might gain recognition, protection and rights (Ibid).

\section{Objective of the Study}

* The main objective of this study was to identify the challenges of multiculturalism in general and the problems of multicultural co-existence in Ethiopia.

\section{Methodology \\ 4.1 Research Approach}

In order to investigate the issues of multicultural co-existence in Ethiopia and identify the different facets of multiculturalism the study employed qualitative research approach. Qualitative research approach is typical research approach which enables to come up with data that cannot be easily produced by statically procedure or the means of quantification. It is associated with a variety of the theoretical perspectives, uses arrange of method in order to focus on meaning and interpretation social phenomenon and social process in the particular context in which they occur (Strous and Corbin, 1998). Qualitative research explores and understands the measuring of individuals or groups ascribed to social or human problems (Creswell, 2009).

\subsection{Research Design}

The research design is the master plan of a research that shows the way to have the study is conducted. For this study, case study research design was employed. Case study design offers comprehensive coverage of the design and use the case study method as a valid research tools (Robert, 2013). The rationale behind using case study design was to collect appropriate data in depth study of a particular situation in word rather than a sweeping statically survey.

\subsection{Sources of Data}

In this study, secondary sources of data were applied. That is, data from available literature, books, journal articles, magazines, and report prepared by research Scholars, historical document, legal documents, public records and news paper were used.

\subsection{Data Analysis}

For this study qualitative method of analysis was used. To collect all relevant data for this study the researcher used document review analysis from different related literature, books, journal articles, magazines, and report prepared by research Scholars, historical document, legal documents, public records and news paper.

\section{Discussions}

\subsection{Forms of Multiculturalism:}

As it is obvious, the term multiculturalism has number of meanings and has been used in a variety of ways. Some 
critics feel that it is difficult to define multiculturalism exactly. Andrew Heywood() talks about two forms of multiculturalism. They are descriptive and normative. As a descriptive term, it has been taken to refer to cultural diversity and as a normative term, multiculturalism implies a positive endorsement, even celebration of communal diversity, typically, based on either the rights of different groups to respect and recognition or to the alleged benefits to the larger society of moral and cultural diversity (Heywood 313). The first form only refers and registers the presence of various groups, whereas the second expects to do something not only to maintain the minority identity, but to help them to improve.

Ashok Chaskar in his book Multiculturalism in Indian Fiction in English identified different forms of multiculturalism.

i. Democratic multiculturalism recognizes the reality of cultural diversity and differences and gives them a political dimension. These differences can give rise to clashes between groups but democratic multiculturalism attempts to resolve conflicts through dialogue and discussion. It assumes that social equality is possible only when there is no oppression and subordination. The focal themes of democratic multiculturalism are social heterogeneity, diversity and freedom. It advocates the politics of involvement.

ii. Conservative multiculturalism which is less accommodative than the other forms. Liberal multiculturalism celebrates the value of individualism. Liberty and autonomy are terms dear to it, but it denies the issues of identity and belonging. Its argument is for a natural equality of all.

iii. Critical multiculturalism focuses itself on the importance of the positive socio- cultural transformations. It supports the representation of race, class and gender in the public domain and understands the reasons of social unrest and struggles.

\subsection{The Significance of Multicultural Co-existence}

According to Kim Kyung-hyun multiculturalism is a recent coinage that literally refers to the state of coexistence in a society of multiple cultures of race, ethnicity, religion gender and sexuality. Multiculturalism tells us that we are lightly different from each other; at last we all are one. Multiculturalism brings together the set of issues like sense of belongingness, sense of identity, status and recognition, need to recognize and maintain difference with others. It allows immigrant groups to follow their own customs, regarding food, dress, religion and association with others. Peter Schuck in his Diversity in America points out that multiculturalism is a particular way to understand, to express and to institutionalize the identity in an ethnically diverse society.

Multiculturalism is a fact today. There are more than six thousand communities and as many languages in today's world. It naturally leads to the diversity of vision, practice, belief values, etc. Multiculturalism is a way of life living together but appreciating cultural life of others. It expects dialogues among many groups. It is neither to idealize nor to reject other. Multiculturalism expects inactions, strong moral cohesion, and social responsibilities. If there is prejudice, against other, the clash between 'Them and Us' increases, which results into communal riots. This automatically hampers the development of nation. So for nation's cause, multiculturalism talks of unity in diversity. Multiculturalism requires two things; the equality of opportunity and proportional representation. The idea of multiculturalism promotes societies having inter-ethnic, inter-racial harmony, respect for cultural difference. Multiculturalism is valuable because it uses several disciplines to highlight neglected aspect of our social history, particularly the histories of women and minorities, etc. and promotes respect for the dignity of the lives and voices of the forgotten. By closing gaps, by raising consciousness about the past, multiculturalism tries to restore a sense of wholeness in a postmodern era that fragments human life and thought.

It is a school of thought that advocates society to provide parallel status to distinct cultural and religious groups. No culture is entirely perfect or any entirely worthless. Cultures evolve over times and this process has been continued. It is a term which describes the coexistence of many cultures in a locality without any one culture dominating the region by making the broadest range of human differences acceptable to the largest number of people, and most significantly multiculturalism seeks to overcome racism, sexism and other forms of discrimination (Ibid).

Will Kymlicka in the book Multicultural Citizenship writes, "the basic premise of multiculturalism is that membership in a cultural community is essential to our personal identity and provides individuals with the necessary framework to exercise their true liberty' $(82,83)$. Tariq Modood supports multiculturalism in his book Multiculturalism: A Civic Idea polity saying that in the early years of the 21 st Century, multiculturalism is mask timely and necessary and ... we need more not less, since it is the form of integration, it best fits the ideal of egalitarianism, it has remained moderate and pragmatic. Multiculturalism helps to maintain a stable identity having interaction with and contribution of cultural groups, preserving difference.

As there is much diversity in many counties of the world, it becomes essential to develop a national personality without disturbing the individual religious and ethnic identity. To maintain harmony, the groups need to interact. Mahatma Gandhi said, 'No culture can live if it attempts to be exclusive'. The respect for other cultures and celebration of diversity would prevent culture clashes and terrific war, so multiculturalism has become the need of time. The nation building gets affected and weakened, if diverse ethnic groups clash with each other. 


\subsection{Challenges of Multiculturalism}

According to Malory Nye (2015) he has briefly explained the challenges of multiculturalism. According to him multiculturalism becomes a challenge because;

\section{A. It is Specific}

Multiculturalism is a process, and such processes are always contextual to particular places and cultural experiences. Thus, we have to recognize that the experiences of multiculturalism in a particular country are unique to that country, and is different from multiculturalism in other countries. This means that our analysis and understanding of multiculturalism in each of these contexts must also be contextual, and we should not try to understand one within the framework of the other. The distribution and mix of population in each country is specific, as of course are migration histories, and the histories of relations between groups within the multicultural context. It is of course very important to relate the particular experiences of multiculturalism to the ways in which issues of diversity and change are perceived within the national context of the society. In short, no single model of multiculturalism, for example, from a European or American context, will be applicable within the context of an Arabian Gulf state or in Southeast Asia.

\section{B. They are Temporary and Liable to Change}

As multiculturalism is process, it is very important to recognize that relations between groups and people within any multicultural context are subject to change and development. This might work either positively or negatively. The context of peaceful and respectful relationships between different groups might not last indefinitely, and examples such as the Balkans (the former Yugoslavia) in the 1990s and Sri Lanka over the past few decades give stark examples of how peaceful co-existence may be subject to manipulation and violent disruption.

\section{They have Tensions Built into Them}

No society today is homogeneous, and so all societies in the contemporary globalised world have factors of diversity and difference. Such differences are not only cultural or religious differences; there are many other factors of social diversity, which may equally impact. These differences need to be managed effectively, and in particular the respect for diversity needs to be combined with the creation and development of a sense of common ground across the differences. Otherwise the potential tensions of diversity can become serious, particularly within the context of public debates and perceptions. Difference can become politicized in many different ways, particularly at times of rapid social change or economic or political crisis.

\section{They are not always Peaceful and Disruptions are Sometimes Unavoidable}

Sometimes the above two issues can lead to more than tension, and cultural diversity can lead to cultural conflict within a society, particularly in a context where such diversity also reflects other differences of power, income, wealth, education and access to resources. Multiculturalism is not necessarily about preventing such conflict, but rather one of the challenges of multiculturalism is to ensure that any intercultural conflict within society is manageable, and at the same time ensures the application of social justice and protection to all parts of the society. Those who argue against espouse that cultural diversity is something which is a source of social disharmony, conflict, and then an impediment to economic growth. They characterize culturally diverse society is mutually suspicious, less charitable, less altruistic, less cooperative to infrastructure and dominated by ethnic nepotism. We act like turtles. The effect of diversity is worse than had been imagined. And it's not just that we don't trust people who are not like us. In diverse communities, we don't trust people who do look like us. Recommendation of anticultural diversity proponents is, at best, to abolish cultural diversity in a given jurisdiction, and at worst, to minimize it (Dessalegn Amsalu, 2010).

\subsection{Challenges of Co-existence in a Multicultural Ethiopian Society}

National co-existence is the awareness of a common identity amongst the citizens of a country. Though there different ethnic groups and religions and speak different languages, recognizing living in a peaceful manner as all in one (Kenedy and Eremie, 2016). This kind of integration is very important in the building of a strong and prosperous nation. Multiculturalism in Ethiopia rooted in the in the social and political history of the country. In the early 1990s multiculturalism has become a topic of discussion among Ethiopians both at government and societal levels. Ethiopia has been described as home for different cultural groups whose population is characterized by a enormous pattern of ethnic, linguistic and religious groups. These aspects of diversity are considered to be significant distinguishing features of the country.

According to Leulseged Tadesse in his article, can diversity be accommodated, raised institutional efficiency gap as a major shortfall for the co-existence of multicultural Ethiopian society. There is a need for efficient federal and democratic institutions to effectively and continually consolidate the success of a complex society such as that of Ethiopia. This institutional efficiency gap manifests itself in the following ways: lack of good governance and strong democratic institutions; lack of institutions that deal with intergovernmental relations; and lack of efficiency in the existing institutions, or even absence of strong democratic institutions, has negatively affected the performance of the federal system in its struggle to accommodate diversity. Democracy promotes and accommodates pluralism. In Ethiopia, because of the inefficiency of democratic institutions and a lack of good 
governance many conflicts happened in between the different cultural groups.

The core challenge of a multicultural state is the conflict that inevitably arises from an attempt to harmonize different cultures, languages, ethnic groups and religions. Since the fall of the Berlin Wall this concept has become a fundamental challenge with increasingly brutal intra-State conflicts posing threats to the stability of states and the international community and thereby posing pitfalls on the co-existence of cultural groups (Ojeah, 2018).

\section{Conclusion}

As culture is a socially constructed and learned phenomena which is comprised of elements like language, values and norms, multiculturalism is a society, state, a nation, a country, a region or even a geographical location as town or school, which is composed of people who belong to different cultures. There are three forms of multiculturalism, i.e. democratic, conservative and critical. Multiculturalism is important since it promotes one to keep his or her own identity, it can avoid marginalization that resulted because of neglected past history, can create harmony in between inter- ethnic and inter- racial identities and also consolidates representation in one's own identity in the political sphere of a country. However multiculturalism is not free of obstacles. It is temporary and viable to change. Multiculturalism exposed for tensions between the different cultural identities. In a multicultural society peace is not permanent which means disruptions are common. Ethiopia is a sign of multiculturalism with rich diverse cultural groups living as one nation. But this fact is not free of challenges. There are a number of factors threatening this value. The presence of institutional gap, lack of efficiency coupled with extreme ethnic feelings are the main sources of the problem among others that can deter multicultural co- existence in Ethiopia.

\section{Recommendation}

It is believed that multiculturalism is important since it promotes one to keep his or her own identity, it can avoid marginalization that resulted because of neglected past history, can create harmony in between inter- ethnic and inter- racial identities and also consolidates representation in one's own identity in the political sphere of a country. Therefore, the study recommended that awareness is so paramount and as a result people can consider that culture or identity is relative to the society so that none is superior or inferior over the other. So to do this government, civil societies and other stakeholders should strongly work to alleviate the problem. As a result multiculturalism would become a source of beauty and income to the Ethiopian people.

\section{References}

Abebaw Yirga(2014). Ethnic and Religious Diversity in Higher Education in Ethiopia: The Case of Bahir Dar University.

Christopher M. and Franco B.(2004). The Economic and Social Impact of Cultural Festivals in the East Midlands of England. De Montfort University, Leicester.

Desalegn Amsalu(2010). Cultural Diversity, Opportunities, and Management: Ethiopia in Perspective. Addis Ababa.

Final MDG-F Joint Programme Narrative Report(2013). Harnessing Diversity f or Sustainable Development and Social Change, Ethiopia.

Greg R., Marisap B. and Linda W.,(2013). The Social Impacts of Events. The Need to Understand the Social Dimensions of Events. New York, NY 10017.

Insunn S., Charles A., and Timothy J.(2012). Key Characteristics of Multicultural Festivals: A Critical Review of the Literature. School of Tourism, University of Queensland, Brisbane, Australia. Event Management, Vol. 16, pp. 93-101.

Kennedy M.and Eremie M. (2016). Co- Existence in Nigeria Society: Implication for Counseling.

Kymlicha W. (1995). Multicultural Citizenship. A Liberal Theory of Minority Rights. Great Clarendon Street, Oxford ox 2 6DP.

Leulseged Tadesse. Can Diversity be Accommodated? The Case of Ethiopia. Policy Issues in Federalism: International Perspectives.

Maryanne N.(2017). Constructing Identity through Cultural Festivals in Kenya. Unpublished Master's Thesis. University of Pretoria. Pretoria.

Mendible M. (1999). What is multiculturalism? St. James Encyclopedia of Popular Culture, Gale Group.

Nye M.(2007). The Challenges of Multiculturalism. Culture and Religion. 2007, Vol 8 No 2.

Ojeah V. (2018).The Challenges of a Multicultural State.

Raz J. (1998). Multiculturalism. Ratio Juris. Vol. 11 No. 3 September (193-205).

Tjarve B., Zemìte I. (2016). The Role of Cultural Activities in Community Development. Acta Universitatis Agriculturae et Silviculturae Mendelianae Brunensis, 64(6): 2151-2160. 


\section{Online sources}

https://ich.unesco.org/en/convention Retrieved on 8/7/2019 At 8:27 PM

https://www.ethioembassy.org.uk/12th-nations-nationalities-and-peoples-day-celebrated-colourfully-in-london/ Retrieved on 8/7/2019 at 3:51 AM

http://www.ecsu.edu.et/article/13th-nations-nationalities-and-peoples-day-celebrated-ecsu Retrieved on 8/7/2019 at 3:45 AM

https://festivals.awesomeji.com/national-festivals.html Retrived on 8/7/2019 at 3:36 AM

https://www.amu.edu.et/index.php?option $=$ com_content\&view $=$ article \&id=473:about-ethiopian-nationsnationalities-and-peoples-day-celebration\&catid=1:amu\&Itemid=244 Retrieved on 8/7/2019 at 3:56 Am https://allafrica.com/stories/201711290626.html Retrieved on 8/7/2019 at 3:55 AM 